\title{
Chronic Intermittent Hypoxia Elicits Serotonin-Dependent Plasticity in the Central Neural Control of Breathing
}

\author{
Liming Ling, ${ }^{1}$ David D. Fuller, ${ }^{1}$ Karen B. Bach, ${ }^{1}$ Richard Kinkead, ${ }^{1}$ E. Burdette Olson Jr, ${ }^{2}$ and \\ Gordon S. Mitchell ${ }^{1}$ \\ ${ }^{1}$ Departments of Comparative Biosciences and 2Preventive Medicine, University of Wisconsin, Madison, \\ Wisconsin 53706
}

We tested the hypothesis that chronic intermittent hypoxia $(\mathrm{CIH})$ elicits plasticity in the central neural control of breathing via serotonin-dependent effects on the integration of carotid chemoafferent inputs. Adult rats were exposed to 1 week of nocturnal $\mathrm{CIH}$ (11-12\% $\mathrm{O}_{2}$ /air at 5 min intervals; $12 \mathrm{hr} /$ night). $\mathrm{CIH}$ and untreated rats were then anesthetized, paralyzed, vagotomized, and artificially ventilated. Time-dependent hypoxic responses were assessed in the phrenic neurogram during and after three 5 min episodes of isocapnic hypoxia. Integrated phrenic amplitude ( $\int \mathrm{Phr}$ ) responses during hypoxia were greater after $\mathrm{CIH}$ at arterial oxygen pressures $\left(\mathrm{PaO}_{2}\right)$ between 25 and $45 \mathrm{mmHg}(p<0.05)$, but not at higher $\mathrm{PaO}_{2}$ levels. $\mathrm{ClH}$ did not affect hypoxic phrenic burst frequency responses, although the post-hypoxia frequency decline that is typical in rats was abolished. $\mathrm{P} P \mathrm{Ph}$ and frequency responses to electrical stimulation of the carotid sinus nerve were enhanced by $\mathrm{ClH}$

Although plasticity is a fundamental property of neural systems (Zigmond et al., 1999; Kandel et al., 2000), its significance in the central neural control of breathing in adult mammals has been appreciated only recently (Eldridge and Millhorn, 1986; Mitchell et al., 1990, 1993; McCrimmon et al., 1995; Poon, 1996a,b; Powell et al., 1998). In this study, we demonstrate the existence of novel forms of serotonin-dependent plasticity in the hypoxic ventilatory control system elicited by chronic intermittent hypoxia.

The hypoxic ventilatory response in mammals consists of several time-dependent facilitatory and inhibitory mechanisms that are revealed by different patterns and durations of hypoxia (Bisgard and Neubauer, 1995; Powell et al., 1998). In anesthetized rats, a single 5 min hypoxic episode increases phrenic nerve activity, an effect known as the short-term hypoxic phrenic response. When normoxia is restored, phrenic burst frequency decreases below the original baseline level and returns to baseline over several minutes (post-hypoxia frequency decline) (Coles and Dick, 1996; Bach et al., 1999).

\footnotetext{
Received July 14, 2000; revised May 2, 2001; accepted May 3, 2001.

This work was supported by National Institutes of Health (NIH) Grants HL53319 and HL65383. L.L. and D.D.F. were supported by NIH Training Grant HL07654. R.K. was supported by a postdoctoral fellowship from the Medical Research Council (Canada).

Correspondence should be addressed to Dr. Gordon S. Mitchell, Department of Comparative Biosciences, University of Wisconsin, 2015 Linden Drive West, Madison, WI 53706. E-mail: Mitchell@svm.vetmed.wisc.edu.

L. Ling's present address: Sleep Disorders Center, Brigham and Women's Hospital, Harvard Medical School, Boston, MA 02115.

R. Kinkead's present address: Unite de Recherche de pediatric, Centre Hospitalier Universitaire de Quebec, Quebec, G1L 3L5 Canada.

Copyright (C) 2001 Society for Neuroscience 0270-6474/01/215381-08\$15.00/0
}

$(p<0.05)$. Serotonin-dependent long-term facilitation (LTF) of $\int \mathrm{Phr}$ was enhanced after $\mathrm{ClH}$ at 15, 30, and 60 min after episodic hypoxia $(p<0.05)$. Pretreatment with the serotonin receptor antagonists methysergide (4 mg/kg, i.v.) and ketanserin ( $2 \mathrm{mg} / \mathrm{kg}$, i.v.) reversed $\mathrm{ClH}$-induced augmentation of the short-term hypoxic phrenic response and restored the posthypoxia frequency decline in $\mathrm{ClH}$ rats. Whereas methysergide abolished $\mathrm{ClH}$-enhanced phrenic LTF, the selective $5-\mathrm{HT}_{2}$ antagonist ketanserin only partially reversed this effect. The results suggest that $\mathrm{ClH}$ elicits unique forms of serotonindependent plasticity in the central neural control of breathing. Enhanced LTF after $\mathrm{CIH}$ may involve an upregulation of a non-5- $\mathrm{HT}_{2}$ serotonin receptor subtype or subtypes.

Key words: control of breathing; serotonin; plasticity; hypoxia; phrenic motoneurons; rats

A unique form of serotonin-dependent respiratory plasticity, known as phrenic long-term facilitation (LTF), is revealed after repeated hypoxic exposures (Hayashi et al., 1993; Fuller et al., 2000; Mitchell et al., 2001). For example, respiratory motor output remains elevated for at least $60 \mathrm{~min}$ after three hypoxic episodes in anesthetized rats (Bach and Mitchell, 1996; Fuller et al., 2000). LTF requires episodic hypoxia because the same cumulative duration of sustained hypoxia does not elicit this mechanism (Baker and Mitchell, 2000a). Episodic electrical stimulation of the carotid sinus nerve also elicits LTF (Millhorn et al., 1980a; Hayashi et al., 1993) indicating that the underlying mechanism is a central neural process that does not require peripheral chemoreceptor sensitization. Pretreatment with serotonin receptor antagonists (methysergide or ketanserin) (Millhorn et al., 1980b; Bach et al., 1996; Kinkead and Mitchell, 1999) abolishes LTF, thereby demonstrating that serotonin receptor activation is necessary in its underlying mechanism. The relevant serotonin receptors for phrenic LTF appear to be located in the cervical spinal cord (Baker and Mitchell, 2001). Although serotonin receptor activation initiates phrenic LTF, its maintenance requires spinal protein synthesis (Baker and Mitchell, 2000b).

LTF is evoked by relatively few (3-10) stimulus episodes (Millhorn et al., 1980a; Turner and Mitchell, 1997; Fuller et al., 2000). We wondered if exposure to additional hypoxic episodes [i.e., chronic intermittent hypoxia $(\mathrm{CIH})]$ would reveal additional plasticity in time-dependent hypoxic phrenic responses. Accordingly, these experiments tested the hypothesis that $\mathrm{CIH}$ alters subsequent phrenic responses during and after three hypoxic episodes and that the resulting plasticity is serotonin-dependent. The re- 
Table 1. Arterial blood gases during experimental protocols

\begin{tabular}{|c|c|c|c|c|}
\hline & Baseline & Hypoxia & $\begin{array}{l}30 \text { min after } \\
\text { hypoxia }\end{array}$ & $\begin{array}{l}60 \text { min after } \\
\text { hypoxia }\end{array}$ \\
\hline \multicolumn{5}{|l|}{$\mathrm{PaCO}_{2}(\mathrm{mmHg})$} \\
\hline Control & $45 \pm 2$ & $46 \pm 1$ & $45 \pm 2$ & $45 \pm 2$ \\
\hline Control + methysergide & $42 \pm 1^{* *}$ & $42 \pm 1$ & $41 \pm 1^{* *}$ & $42 \pm 1^{* *}$ \\
\hline Control + ketanserin & $44 \pm 1$ & $44 \pm 1$ & $44 \pm 1$ & $44 \pm 1$ \\
\hline $\mathrm{CIH}$ & $39 \pm 1^{* *}$ & $38 \pm 1^{* *}$ & $40 \pm 1^{* *}$ & $40 \pm 1^{* *}$ \\
\hline $\mathrm{CIH}+$ methysergide & $40 \pm 1^{* *}$ & $41 \pm 1$ & $40 \pm 1^{* *}$ & $40 \pm 1^{* *}$ \\
\hline $\mathrm{CIH}+$ ketanserin & $43 \pm 1$ & $43 \pm 1$ & $44 \pm 1$ & $43 \pm 1$ \\
\hline \multicolumn{5}{|l|}{$\mathrm{PaO}_{2}(\mathrm{mmHg})$} \\
\hline Control & $218 \pm 13$ & $33 \pm 1^{*}$ & $210 \pm 13$ & $208 \pm 13$ \\
\hline Control + methysergide & $241 \pm 8$ & N/A & $228 \pm 11$ & $224 \pm 12$ \\
\hline Control + ketanserin & $218 \pm 7$ & $39 \pm 1^{*}$ & $227 \pm 4$ & $222 \pm 6$ \\
\hline $\mathrm{CIH}$ & $214 \pm 10$ & $31 \pm 1^{*}$ & $218 \pm 5$ & $215 \pm 5$ \\
\hline $\mathrm{CIH}+$ methysergide & $200 \pm 11$ & $33 \pm 2^{*}$ & $192 \pm 9$ & $191 \pm 10$ \\
\hline $\mathrm{CIH}+$ ketanserin & $251 \pm 18$ & $38 \pm 3^{*}$ & $245 \pm 12$ & $243 \pm 19$ \\
\hline
\end{tabular}

Values are means \pm 1 SEM. There were no significant differences in $\mathrm{PaCO}_{2}$ within groups.

*Indicates a significant decrease in $\mathrm{PaO}_{2}$ during hypoxic conditions relative to baseline $(p<0.05)$.

** Indicates a significant difference from corresponding $\mathrm{PaCO}_{2}$ value in control rats.

sults suggest a profound capacity in adult mammals for longlasting forms of plasticity in the central neural control of breathing. In many respects, these findings are similar to other models of serotonin-dependent neuroplasticity, in which the pattern and duration of serotonin exposure is a critical determinant of the specific plasticity elicited (Mauelshagen et al., 1998; Yanow et al., 1998).

Portions of this work have appeared in abstract form (Ling et al., 1998, 1999, 2000).

\section{MATERIALS AND METHODS}

The Institutional Animal Care and Use Committee at the University of Wisconsin approved all experimental procedures. Experiments were conducted on male Sprague Dawley rats obtained from Harlan (Madison, WI; colonies 205 or 236b).

Chronic intermittent hypoxia. At 3-5 months of age, rats were exposed to $\mathrm{CIH}$ for seven consecutive nights. The rats were placed in a Plexiglas chamber, which between 6:00 P.M. and 6:00 A.M. was flushed with alternating mixtures of air, $\mathrm{O}_{2}$, and $\mathrm{N}_{2}$ to achieve quasi-square wave intermittent hypoxia [ $5 \mathrm{~min}$ at an inspired oxygen fraction $\left(\mathrm{FIO}_{2}\right)=0.11$ and $5 \mathrm{~min}$ normoxia]. Gas mixtures were flushed at a rate sufficient to attain steady-state gas concentrations within $1 \mathrm{~min}$ and to maintain chamber $\mathrm{CO}_{2}$ concentration $<0.5 \%$. From 6:00 A.M. to 6:00 P.M., the chamber was flushed continuously with air. Rats had ad libitum access to food and water throughout all experimental treatments. On the morning after the final $\mathrm{CIH}$ exposure, the rats were removed from the chamber and transported to the laboratory for acute experiments.

Experimental preparation. Acute neurophysiological experiments were conducted on CIH-treated as well as age-, weight-, and sex-matched control rats. Experiments on treated animals began 4-8 hr after $\mathrm{CIH}$ had ended. Anesthesia was induced with isoflurane in a closed chamber and then maintained via nose cone $\left(2.5-3.5 \%\right.$ isoflurane; $\mathrm{FIO}_{2}=0.5$; balance $\mathrm{N}_{2}$ ). The trachea was cannulated, and the rats were mechanically ventilated while maintaining the inspired isoflurane concentration. Rectal temperature was maintained between 37 and $38^{\circ}$ using a rectal thermistor and a heated table. Bilateral vagotomy was performed in the midcervical region, and rats were paralyzed with pancuronium bromide ( $2.5 \mathrm{mg} / \mathrm{kg}$; supplemented as needed). A femoral venous catheter was inserted for anesthetic and fluid administration. Rats were slowly converted from isoflurane to urethane anesthesia $(1.6 \mathrm{gm} / \mathrm{kg}$, i.v. in distilled water), and the adequacy of anesthesia was assessed frequently by monitoring blood pressure responses to toe pinch.

A femoral arterial catheter (model P23ID; Gould Instruments, Cleveland, $\mathrm{OH}$ ) was placed to allow blood pressure measurements and blood samples for arterial blood gas analysis. Partial pressures of $\mathrm{O}_{2}\left(\mathrm{PaO}_{2}\right)$ and $\mathrm{CO}_{2}\left(\mathrm{PaCO}_{2}\right)$ and $\mathrm{pH}$ were determined with a blood gas analyzer
(ABL-500; Radiometer, Copenhagen, Denmark) from $0.3 \mathrm{ml}$ blood samples drawn into low dead-space heparinized glass syringes; unused blood was returned to the animal. The end-tidal $\mathrm{CO}_{2}$ partial pressure $\left(\mathrm{P}_{\mathrm{ET}} \mathrm{CO}_{2}\right)$ was measured in the expired line of the ventilator circuit using an in-line $\mathrm{CO}_{2}$ analyzer (model 1265; Novametrix, Wallingford, CT) with sufficient response time to measure $\mathrm{P}_{\mathrm{ET}} \mathrm{CO}_{2}$ in rats. At the conclusion of experiments, rats were killed via urethane overdose.

Phrenic nerve recording. The phrenic nerve was isolated using a dorsal approach, cut distally and desheathed. The nerve was placed on bipolar silver wire electrodes, and the signal was amplified $(10,000 \times)$ and filtered (300-10,000 Hz) (model BMA 831, CWE, Ardmore, PA or model 1800, A-M Systems, Carlsborg, WA). The amplified signal was full-waverectified and "integrated" with a Paynter filter (time constant, $50 \mathrm{msec}$; model MA-821RSP, CWE). Signals were digitized and stored on a computer using either commercially available software (WINDAQ, Akron, $\mathrm{OH}$ ) or software developed in our laboratory.

Experimental protocols. After conversion to urethane anesthesia, a minimum of $30 \mathrm{~min}$ was allowed to ensure steady-state $\left(\mathrm{FIO}_{2}=0.5\right.$, balance $\mathrm{N}_{2}$ ). The $\mathrm{CO}_{2}$ apneic threshold for inspiratory phrenic nerve activity was then determined by mechanically hyperventilating the rats until phrenic nerve activity ceased and then slowly decreasing the ventilator rate until inspiratory phrenic nerve activity resumed. The $\mathrm{P}_{\mathrm{ET}} \mathrm{CO}_{2}$ at which inspiratory activity resumed was designated as the " $\mathrm{CO}_{2}$ apneic threshold." $\mathrm{P}_{\mathrm{ET}} \mathrm{CO}_{2}$ was then maintained $3 \mathrm{mmHg}$ above this threshold, adjusting the ventilator rate and/or inspired $\mathrm{CO}_{2}$ as necessary. Because $\mathrm{CIH}$ decreased the apneic threshold, this procedure served to standardize baseline phrenic activity relative to its threshold rather than establishing a predetermined level of $\mathrm{PaCO}_{2}$. Once baseline conditions were established, $30-60 \mathrm{~min}$ were allowed to achieve stable respiratory motor output.

Phrenic responses during and after hypoxia. Time-dependent hypoxic phrenic responses were studied with a protocol used previously in our laboratory (Bach and Mitchell, 1996; Kinkead et al., 1998; Kinkead and Mitchell, 1999). Using this protocol, experiments were conducted on 10 control and $11 \mathrm{CIH}$ rats. Additional experiments were conducted on separate groups of control and $\mathrm{CIH}$ rats after pretreatment with methysergide maleate $(4 \mathrm{mg} / \mathrm{kg}$, i.v. in saline vehicle; $\sim 20 \mathrm{~min}$ before the first hypoxic episode; control, $n=10$ and $\mathrm{CIH}, n=6$ ) or ketanserin tartarate $(2 \mathrm{mg} / \mathrm{kg}$, i.v. in saline vehicle; $\sim 20 \mathrm{~min}$ before the first hypoxic episode; control, $n=13$ and $\mathrm{CIH}, n=5$ ). After establishing baseline, rats were exposed to three $5 \mathrm{~min}$ isocapnic hypoxic episodes $\left(\mathrm{FIO}_{2}=0.10-0.15\right)$, separated by $5 \mathrm{~min}$ hyperoxic intervals $\left(\mathrm{FIO}_{2}=0.50\right)$. Phrenic nerve activity was monitored throughout the hypoxic exposures and for $1 \mathrm{hr}$ after hypoxia while maintaining isocapnic conditions with respect to baseline $\mathrm{PaCO}_{2}$. A hypercapnic response test $\left(\mathrm{P}_{\mathrm{ET}} \mathrm{CO}_{2}, \sim 80-90 \mathrm{mmHg}\right)$ was done at the conclusion of each experiment. Arterial blood samples were drawn during baseline, the initial hypoxic episode, and 15, 30, and 60 min after episodic hypoxia. $\mathrm{PaCO}_{2}$ and $\mathrm{PaO}_{2}$ values during this 
protocol are presented in Table 1 . The severity of hypoxia within a range of $25-60 \mathrm{mmHg}$ does not influence the magnitude of LTF $60 \mathrm{~min}$ after hypoxia (Fuller et al., 2000). During these experiments, the short-term hypoxic phrenic response was quantified (see below) during the first hypoxic episode, post-hypoxia frequency decline was quantified after the first hypoxic episode, and LTF was quantified 15, 30, and $60 \mathrm{~min}$ after the final hypoxic episode.

Additional experiments were conducted on control and $\mathrm{CIH}$ rats in which only the short-term hypoxic phrenic response was measured at several levels of $\mathrm{PaO}_{2}$. Short-term hypoxic phrenic response data from these experiments were combined with data from the LTF protocol described above, resulting in the following groups: $30 \pm 1 \mathrm{mmHg}$ (control, $n=9$; CIH, $n=12$ ), $40 \pm 1$ (control, $n=19$; CIH, $n=11$ ), $50 \pm$ 1 (control, $n=8$; CIH, $n=6$ ), and $60 \pm 1$ (control, $n=7$; CIH, $n=6$ ).

Carotid sinus nerve stimulation. The carotid sinus nerve stimulation protocol has been described in detail previously (Ling et al., 1997). Briefly, the left carotid sinus nerve was isolated via a dorsal approach, cut distally, and mounted on a fine bipolar silver wire electrode (control, $n=$ 10; $\mathrm{CIH}, n=6$ ). The stimulation current threshold was established in each experiment by determining the minimum current necessary to elicit a repeatable response in phrenic nerve activity $(20 \mathrm{~Hz}, 0.2 \mathrm{msec}$ duration). The stimulation current was then set at $3 \times$ this threshold current for the duration of the experiment. Thus, the carotid sinus nerve was stimulated (S88 Stimulator; Grass Instrument Company, Quincy, MA) with constant currents $(20-180 \mu \mathrm{A})$ at varied frequencies $(0.5-20 \mathrm{~Hz} ; 0.2$ msec pulse duration). Stimulus frequency was changed sequentially in nine, $45 \mathrm{sec}$ stimulation episodes: $0.5,1,2,5,8,11,14,17$, and $20 \mathrm{~Hz}$. To test whether responses to carotid sinus nerve stimulation were secondary to current spread, we crushed the proximal end of the carotid sinus nerve at the conclusion of three experiments and determined that phrenic responses could no longer be evoked by stimulation. After the final stimulus episode, a hypercapnic phrenic response was determined $\left(\mathrm{P}_{\mathrm{ET}} \mathrm{CO}_{2}=85-95 \mathrm{mmHg}\right)$.

Data analyses. During acute experiments, peak integrated phrenic amplitude ( $\left.\int \mathrm{Phr}\right)$ and phrenic burst frequency $(f)$ were averaged over 30 $\mathrm{sec}$ intervals immediately before the first hypoxic episode (baseline), at the conclusion of each hypoxic episode, 15,30 , and $60 \mathrm{~min}$ after episodic hypoxia, and at the conclusion of the hypercapnic response. In experiments in which only the short-term hypoxic phrenic response was assessed, phrenic nerve activity was averaged over $30 \mathrm{sec}$ intervals at baseline and the conclusion of each hypoxic exposure. Phrenic burst frequency was averaged in $20 \mathrm{sec}$ "bins" for $5 \mathrm{~min}$ after hypoxia and expressed as a change from baseline to assess post-hypoxia frequency decline. Changes in $\int \mathrm{Phr}$ during or after hypoxia were expressed relative to $\int \mathrm{Phr}$ during both baseline and hypercapnic (i.e., maximal activity) conditions. Expressing changes in $\int \mathrm{Phr}$ relative to both the baseline and a standardized maximum level of activity serves to minimize concerns regarding potential normalization artifacts that may occur when comparing neurograms within and between rats. All $\int \mathrm{Phr}$ data are presented as percentage of change from baseline because all responses (and conclusions) were similar regardless of the normalization used. Frequency data are expressed as a change from baseline (bursts per minute); this change is referred to as the frequency response throughout the manuscript.

Two-way ANOVA with repeated measures design was used to make statistical inferences (SigmaStat version 1.0; Jandel Corporation, San Rafael, CA), followed by a post hoc test (Student-Newman-Keuls) to identify individual differences between rat groups or times after hypoxia within a group. Statistical inferences concerning differences between experimental groups with only one variable (e.g. $\mathrm{CO}_{2}$ apneic threshold) were made with Student's $t$ tests. Differences were considered significant if $p<0.05$. All data are presented as mean \pm 1 SEM.

\section{RESULTS}

\section{$\mathrm{CO}_{2}$-apneic threshold}

The $\mathrm{CO}_{2}$-apneic threshold for inspiratory phrenic activity was significantly lower $(p<0.00001)$ in CIH-treated $(36 \pm 1 \mathrm{mmHg}$; $n=22$ ) versus control rats (42 $\pm 1 \mathrm{mmHg} ; n=23)$. Accordingly, baseline $\mathrm{PaCO}_{2}$ values were lower in CIH rats (Table 1).

\section{Hypoxic phrenic responses}

Representative examples of phrenic responses to episodic hypoxia from one control and one $\mathrm{CIH}$ rat are shown in Figure 1. The relative change in $\int \mathrm{Phr}$ during hypoxia is significantly greater

\section{A. Control}
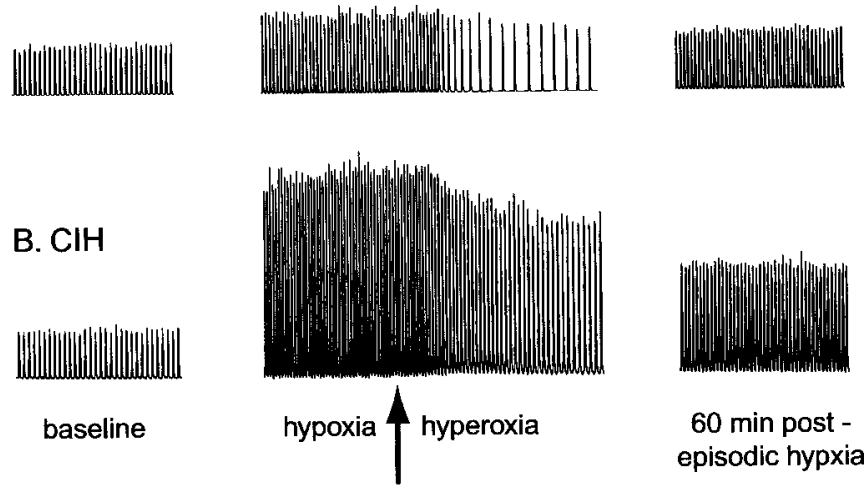

Figure 1. Representative tracings of the integrated phrenic neurogram before (baseline), during hypoxia, the return to hyperoxia (arrow), and 60 min after three isocapnic hypoxic episodes in one control $(A)$ and one $\mathrm{CIH}$ rat $(B)$. Such tracings allow an assessment of the short-term hypoxic phrenic response (during hypoxia), the post-hypoxia frequency decline (shortly after return to hyperoxia), and LTF (60 min post-episodic hypoxia). CIH augmented the short-term hypoxic phrenic response, eliminated the post-hypoxia frequency decline, and enhanced phrenic LTF.

in the $\mathrm{CIH}$ rat, indicating an augmentation of the short-term hypoxic phrenic response. In addition, post-hypoxia frequency decline after the first hypoxic episode is obvious in the control rat, but virtually absent after CIH. Finally, the magnitude of LTF is greater in the $\mathrm{CIH}$ versus control rat; $\int \mathrm{Phr}$ is greater at all times after episodic hypoxia.

\section{Short-term hypoxic phrenic response}

Average short-term hypoxic phrenic responses in CIH and control rats are shown in Figure 2. CIH augmented the short-term hypoxic phrenic response, but only within a limited range of $\mathrm{PaO}_{2}$. In control rats, the change in $\int \mathrm{Phr}(\%$ baseline) during hypoxia increased until $50 \pm 1 \mathrm{mmHg} \mathrm{PaO}_{2}$; at this level of hypoxia, the short-term hypoxic phrenic response was an $\sim 100 \%$ increase from baseline. At lower levels of $\mathrm{PaO}_{2}$, further increases in $\int \mathrm{Phr}$ were not observed. At $50 \mathrm{mmHg} \mathrm{PaO}_{2}$ and above, $\mathrm{CIH}$ had no effect on the short-term hypoxic phrenic response. On the other hand, at more severe levels of hypoxia, $\mathrm{CIH}$ augmented the short-term hypoxic phrenic response progressively, reaching a value $>200 \%$ above baseline at $30 \pm 1 \mathrm{mmHg} \mathrm{PaO}_{2}$. Thus, as the hypoxic stimulus became more severe, $\mathrm{CIH}$-induced functional enhancement of the short-term hypoxic phrenic response was revealed. However, changes in phrenic burst frequency during hypoxia were not different between control and $\mathrm{CIH}$ rats at any level of hypoxia $(p>0.05)$ (Fig. 2).

Although pretreatment with the serotonin receptor antagonist methysergide has no effect on the short-term hypoxic phrenic response in control rats (Fig. 3) (Bach and Mitchell, 1996), virtually all of the CIH-induced augmentation was reversed by this drug (Fig. 3). Thus, methysergide restored the short-term hypoxic phrenic response of $\mathrm{CIH}$ rats to control levels, indicating that this form of respiratory plasticity requires the activation of serotonin receptors. Similarly, although the more selective $5-\mathrm{HT}_{2}$ receptor antagonist ketanserin has no effect on the short-term hypoxic phrenic response in control rats (Fig. 3) (Kinkead et al., 1999), virtually all of the CIH-induced augmentation was reversed by this drug (Fig. 3). However, the levels of $\mathrm{PaO}_{2}$ during hypoxia in ketanserin-treated control and $\mathrm{CIH}$ rats were slightly higher than 

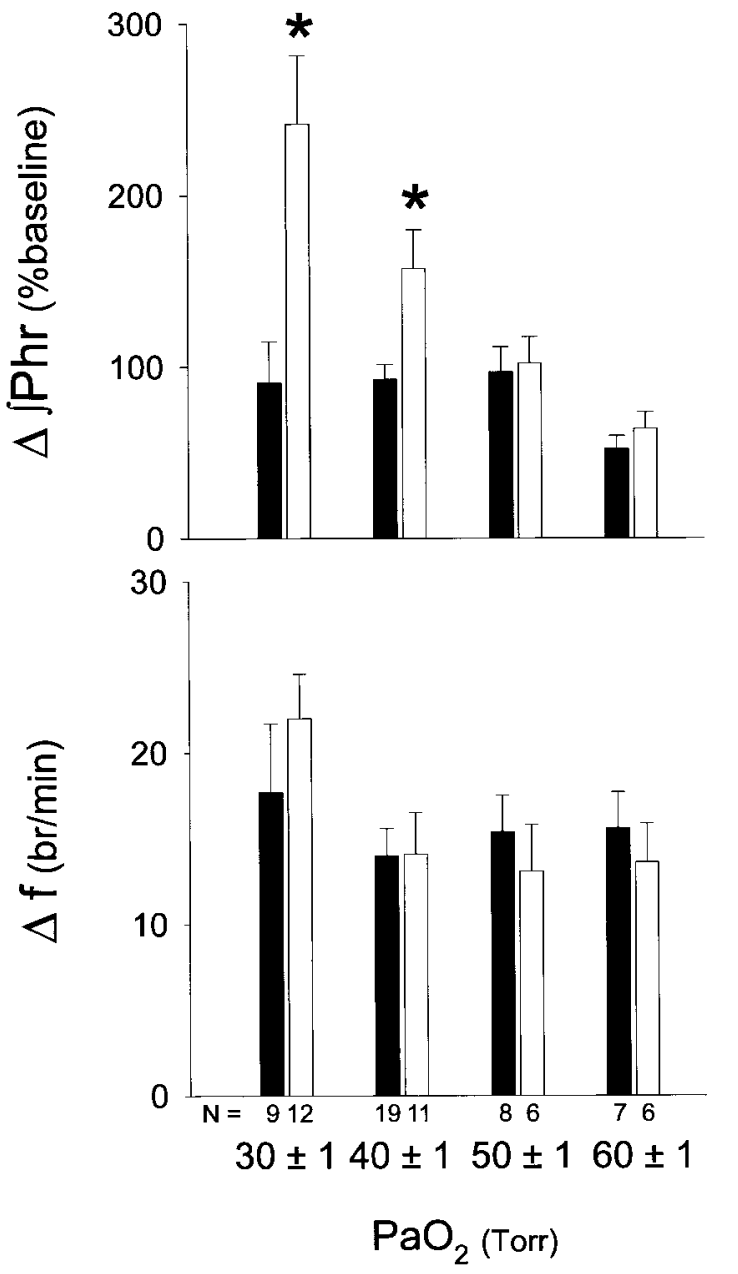

Figure 2. Changes in integrated phrenic amplitude ( $\int \mathrm{Phr}$; percentage of baseline) and burst frequency ( $f$, bursts per minute) during hypoxia in control (solid bars) and $\mathrm{CIH}$ (open bars) rats. The short-term hypoxic phrenic response (change in $\int \mathrm{Phr}$ ) was significantly enhanced in $\mathrm{CIH}$ rats at the two most severe hypoxic levels, but not at $\geq 50 \mathrm{mmHg}$. The hypoxic frequency response (change in $f$ ) was unaffected by $\mathrm{CIH}$ at any level of hypoxemia. Values are means \pm 1 SEM. For explanation of hypoxic groups, see Materials and Methods. *Indicates a significant difference between $\mathrm{CIH}$ and control rats $(p<0.05)$.

the other groups compared in Figure 3 (38-39 vs $32-33 \mathrm{mmHg}$, respectively). Nevertheless, the CIH-induced enhancement of the short-term hypoxic phrenic response is significant even at 40 mmHg (Fig. 2). Thus, it appears that $\mathrm{CIH}$ augments the shortterm hypoxic phrenic response by a serotonin-dependent mechanism associated with the activation of $5-\mathrm{HT}_{2}$ receptors.

\section{Post-hypoxia frequency decline}

In control rats, phrenic burst frequency declined rapidly when hypoxia was terminated, transiently decreasing below baseline for at least several minutes (Fig. 4) $(p<0.05)$. CIH eliminated this post-hypoxia frequency decline; frequency declined to, but did not decrease below baseline values in CIH rats (i.e., the change in frequency remained positive in Fig. 4). After methysergide administration, post-hypoxia frequency decline was partially restored in $\mathrm{CIH}$ rats, suggesting that part of the $\mathrm{CIH}$-induced attenuation requires serotonin receptor activation. Pretreatment with ketanserin accentuates the post-hypoxia frequency decline in both normal (Fig. 4) (Kinkead et al., 1999) and CIH-treated

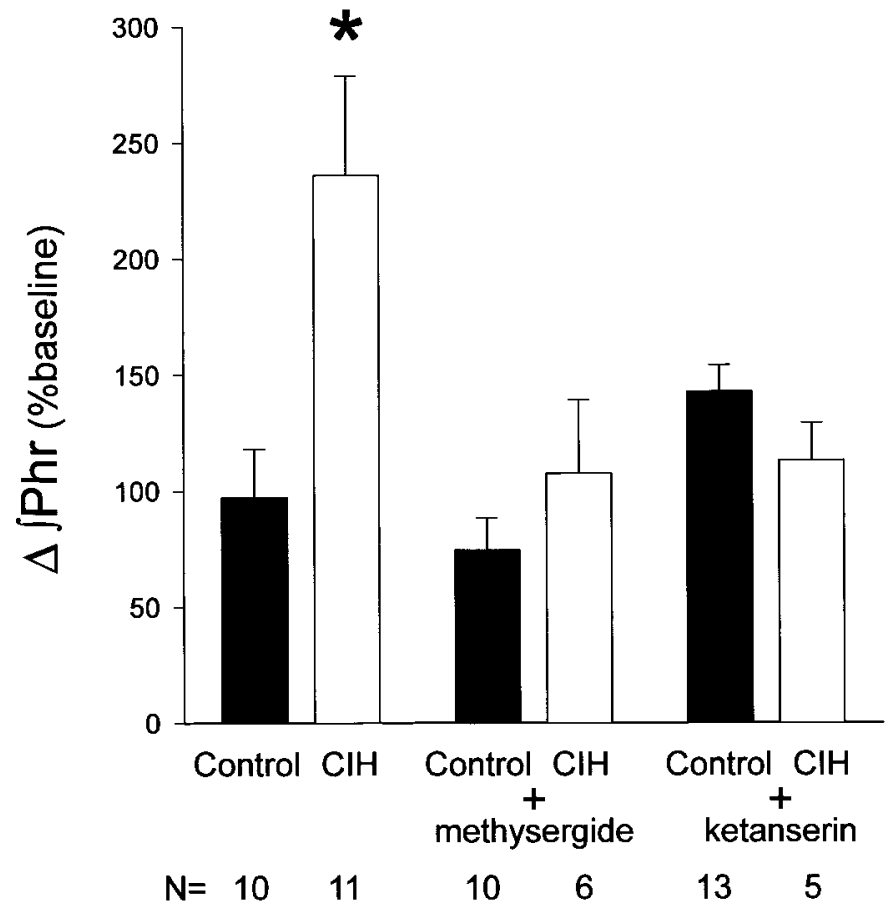

Figure 3. Effects of methysergide and ketanserin on changes in the short-term hypoxic phrenic response ( $\int \mathrm{Phr}$; percentage of baseline) $\left(\mathrm{PaO}_{2}\right.$ values for each group listed in Table 1). Control and $\mathrm{CIH}$ rats were pretreated with methysergide $(4 \mathrm{mg} / \mathrm{kg}$, i.v.) or ketanserin $(2 \mathrm{mg} / \mathrm{kg}$, i.v.) before conducting the standard episodic hypoxia protocol. Methysergide had no effect on the short-term hypoxic phrenic response in control rats but blocked its augmentation in $\mathrm{CIH}$ rats. Data from the control plus methysergide group are from an earlier study (Bach and Mitchell, 1996) in which $\mathrm{PaO}_{2}$ was not measured during hypoxia. Ketanserin also had no significant effect on the short-term hypoxic phrenic response in control rats but blocked its augmentation in CIH rats. Data from the control plus ketanserin group are from earlier studies (Kinkead et al., 1999; Fuller et al., 2001). Although in the control, CIH, and methysergide plus $\mathrm{CIH}$ groups, mean $\mathrm{PaO}_{2}$ was between 32 and 33, the $\mathrm{PaO}_{2}$ was somewhat higher on average in the ketanserin plus control and ketanserin plus CIH groups (39 and $38 \mathrm{mmHg}$, respectively). Despite these differences, both serotonin receptor antagonists blocked any enhancement of the shortterm hypoxic phrenic response at oxygen levels where the enhancement is significant without the drug (Fig. 2). All values are means \pm 1 SEM. $N$ indicates number of rats per group. * Indicates significant difference from control rats $(p<0.05)$.

rats, indicating that $\mathrm{CIH}$ attenuates the post-hypoxia frequency decline by a mechanism associated with $5-\mathrm{HT}_{2}$ receptor activation.

\section{Long-term facilitation}

The magnitude of phrenic LTF after episodic hypoxia was different in $\mathrm{CIH}$ and control rats (Fig. 5). In control rats, mean $\int \mathrm{Phr}$ was not significantly elevated 15 min after episodic hypoxia, $(p>$ $0.05)$, but gradually increased, becoming significant at 30 and 60 min after episodic hypoxia $(23 \pm 9$ and $38 \pm 8 \%$ above baseline, respectively; both $p<0.05)$. In $\mathrm{CIH}$ rats, $\int \mathrm{Phr}$ was significantly elevated from baseline at $15(65 \pm 10 \%), 30(67 \pm 12 \%)$, and 60 $(81 \pm 13 \%) \mathrm{min}$ after episodic hypoxia (all $p<0.05)$. SPhr was significantly greater in $\mathrm{CIH}$ versus control rats at all times after episodic hypoxia $(p<0.05)$. Thus, CIH enhanced phrenic LTF.

Pretreatment with methysergide blocked the expression of LTF in both control and CIH rats (Fig. 5), indicating that both LTF per se and enhanced phrenic LTF after CIH require the activation of serotonin receptors. Although pretreatment with ketan- 

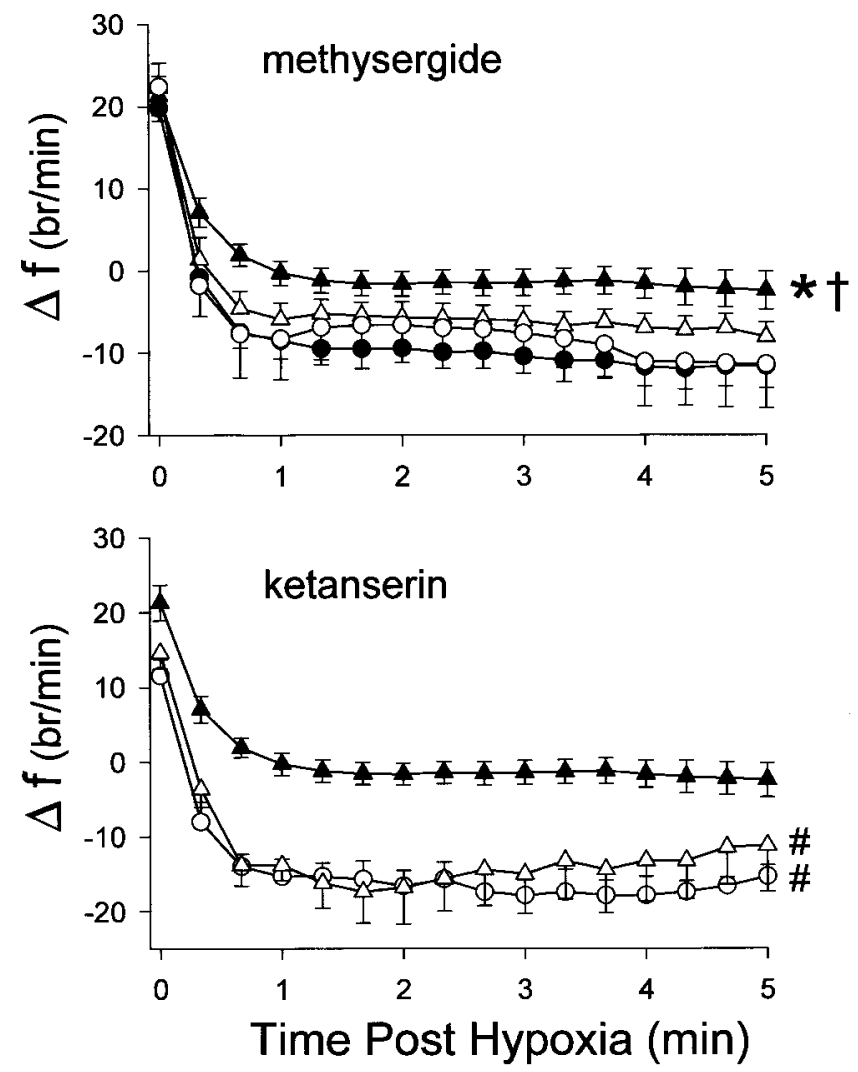

Figure 4. Top, Change in burst frequency ( $f$; bursts per minute) from baseline as a function of time after hypoxia in control (solid circles), $\mathrm{CIH}$ (solid triangles), methysergide pretreated control (open circles), and methysergide pretreated $\mathrm{CIH}$ (open triangles) rats. Bottom, Change in burst frequency from baseline as a function of time after hypoxia in CIH (solid triangles), ketanserin pretreated control (open circles), and ketanserin pretreated $\mathrm{CIH}$ rats (open triangles). Post-hypoxia frequency decline lasted at least $300 \mathrm{sec}$ in control rats but was abolished by CIH. Methysergide had no effect on post-hypoxia frequency decline in control rats, but restored post-hypoxia frequency decline in CIH rats. Ketanserin accentuated the post-hypoxia frequency decline in both control and $\mathrm{CIH}$ rats. Values are means \pm SEM. ${ }^{*}$ Indicates a significant difference between $\mathrm{CIH}$ and control rats $(p<0.05)$. †Indicates a significant difference between $\mathrm{CIH}$ (without drug) and methysergide-treated $\mathrm{CIH}$ rats $(p<$ $0.05)$. \#Indicates a significant difference between ketanserin-treated control or $\mathrm{CIH}$ rats and $\mathrm{CIH}$-treated rats without drug $(p<0.05)$.

serin blocks phrenic LTF in control rats (Fig. 5), it only partially reversed the enhancement of phrenic LTF after CIH (Fig. 5). After ketanserin, LTF in CIH-treated rats was significantly below CIH-treated rats without ketanserin $(p<0.05)$, but still remained significantly greater than baseline 60 min after episodic hypoxia $(p<0.05)$. Thus, although enhanced phrenic LTF after $\mathrm{CIH}$ requires serotonin receptor activation, it seems to do so via non-5- $\mathrm{HT}_{2}$ serotonin receptor subtypes.

\section{Responses to carotid sinus nerve stimulation}

To examine the influence of CIH on central neural integration of carotid chemoafferent inputs, the carotid sinus nerve was stimulated at different frequencies, but at a constant current. Such stimulation will mimic the essential features of hypoxic activation of the carotid body chemoreceptors while bypassing chemosensory transduction (Hayashi et al., 1993). Thus, any changes in the stimulus input-output relationship can be attributed to changes in central neural integration versus changes in peripheral chemoreceptor sensitivity.
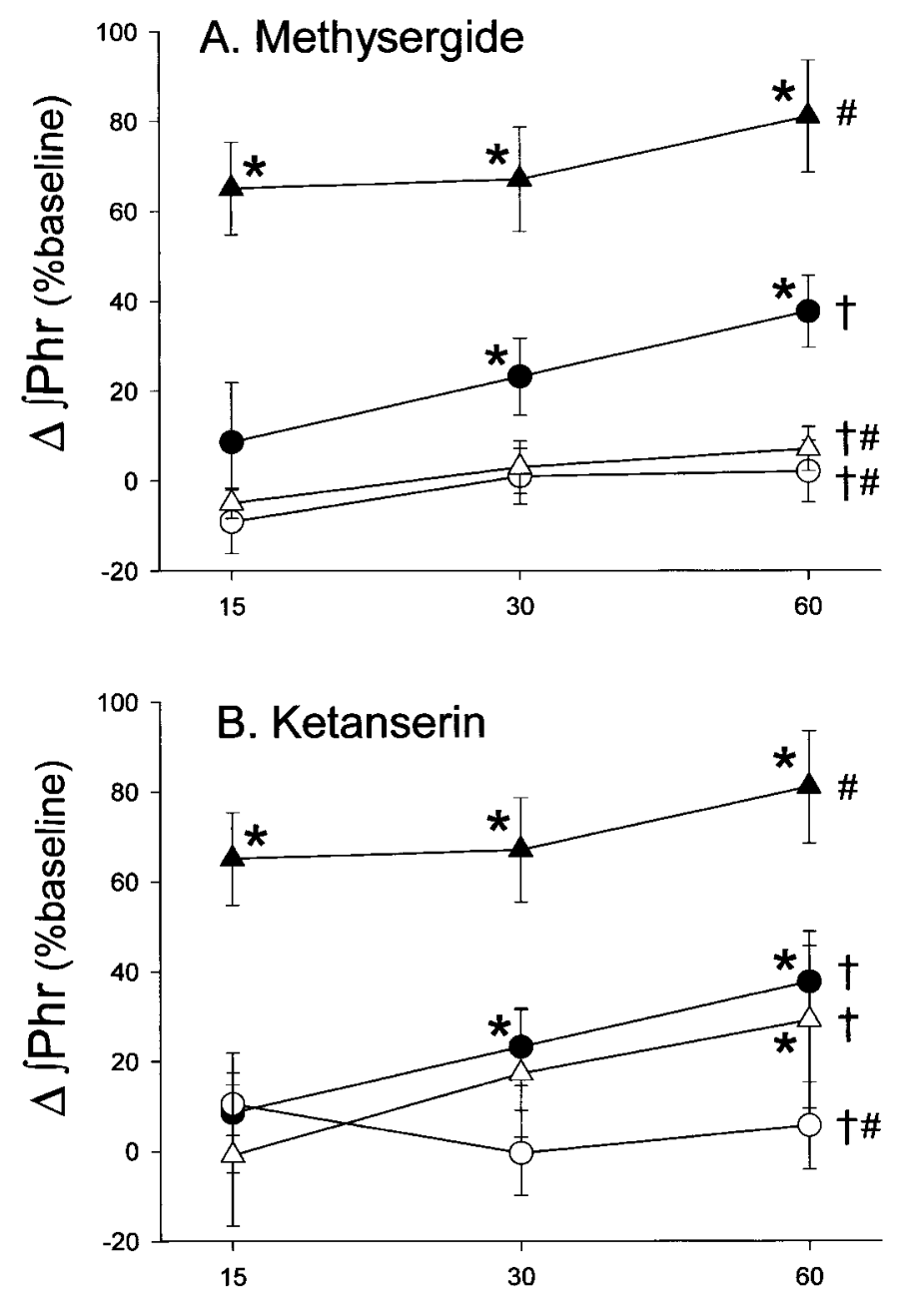

Time Post-Episodic Hypoxia (min)

Figure 5. A, Changes in the peak integrated phrenic neurogram ( $\left.\int \mathrm{Phr}\right)$ after episodic hypoxia. CIH enhances phrenic LTF after three hypoxic episodes by a methysergide-sensitive mechanism. In control rats (solid circles), $\int \mathrm{Phr}$ increased progressively above baseline, indicating the development of LTF. CIH augmented LTF (solid triangles), as indicated by the greater change in $\int \mathrm{Phr}$ at all time points. Methysergide pretreatment abolished LTF in both control (open circles) and CIH-treated (open triangles) rats. $B, \mathrm{CIH}$-enhanced phrenic LTF is only partially reversed by ketanserin. In control rats (solid circles), pretreatment with ketanserin (open circles) abolished LTF. In CIH rats (solid triangles), enhanced phrenic LTF was significantly decreased by ketanserin (open triangles), although LTF remained significant at $60 \mathrm{~min}$ after episodic hypoxia (i.e., significantly higher than baseline). Values are means \pm 1 SEM. * Indicates that $\int \mathrm{Phr}$ is significantly greater than baseline $(p<0.05)$, indicating significant LTF. $†$ Indicates (to the right of curve) a significant difference from $\mathrm{CIH}$-treated rats at the $60 \mathrm{~min}$ time point $(p<0.05)$. \#Indicates (to the right of curve) a significant difference from control rats at the $60 \mathrm{~min}$ time point $(p<0.05)$. Control and CIH-treated rats were significantly different at all time points (data not shown; $p<0.05$ ). The increase from 15 to 60 min was significant for control and $\mathrm{CIH}+$ ketanserin rats (data not shown; $p<0.05)$.

$\int \mathrm{Phr}$ responses to carotid sinus nerve stimulation were markedly enhanced in $\mathrm{CIH}$ versus control rats at all stimulus intensities (Fig. 6) $(p<0.05)$. Although there was a trend for $\mathrm{CIH}$ to augment the frequency response to carotid sinus nerve stimulation, this apparent difference did not attain statistical significance when all data were included in the analysis (Fig. 6) $(p=0.09)$. 

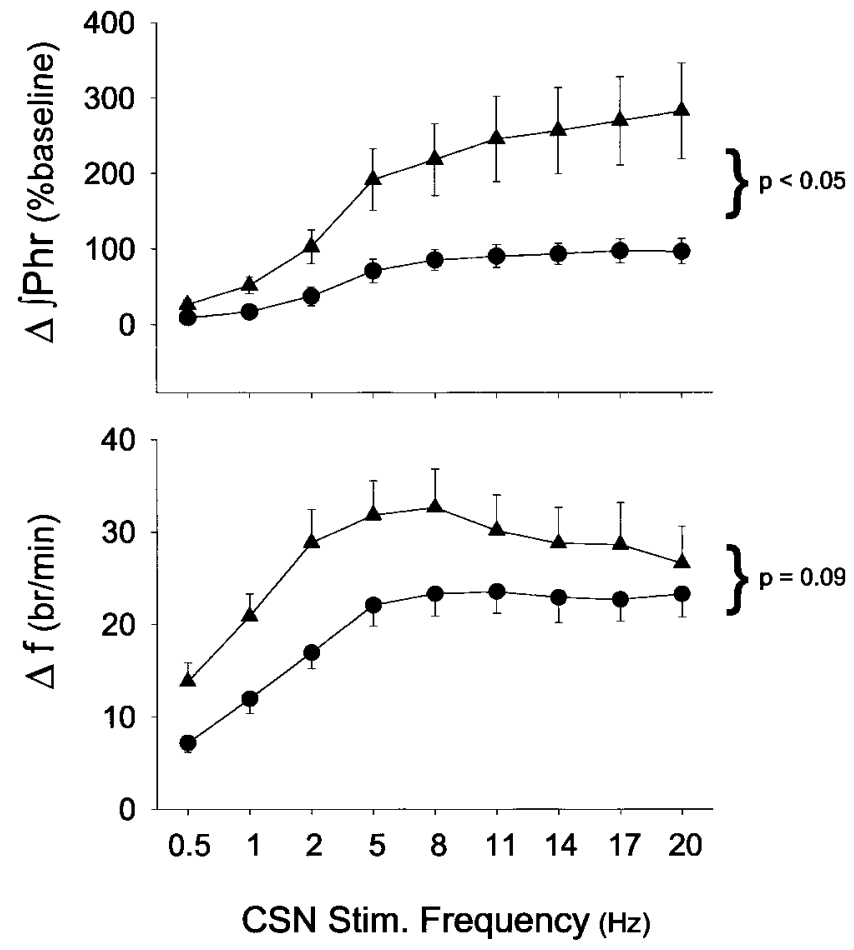

Figure 6. Phrenic nerve responses to electrical stimulation of carotid sinus nerve $(C S N)$ in control (solid circles; $n=10$ ) and CIH (solid triangles; $n=6$ ) rats. Changes in $\int \mathrm{Phr}$ (percentage of baseline) and frequency ( $f$; bursts per minute) during $45 \mathrm{sec}$ stimulation $(3 \times$ threshold) were expressed as functions of stimulus frequency. Data are expressed as means $\pm 1 \mathrm{SEM}$. In the top panel, $\int \mathrm{Phr}$ was significantly greater in $\mathrm{CIH}$ versus control rats at all stimulus frequencies $>1 \mathrm{~Hz}(p<0.05$; shown at right of curves). In the bottom panel, $f$ responses were not significantly different between control and CIH rats $(p=0.09)$; however, the curves were significantly different when the analysis was restricted to stimulation frequencies $<8 \mathrm{~Hz}(p<0.04)$. Values are means \pm 1 SEM.

However, at stimulus frequencies $<8 \mathrm{~Hz}$, the frequency response of $\mathrm{CIH}$ rats is significantly augmented $(p<0.04)$. Stimulus frequencies $<8 \mathrm{~Hz}$ are within the range of frequencies exhibited by single, chemoafferent neurons during hypoxia in rats (Vidruk et al., 2001).

\section{DISCUSSION}

Chronic intermittent hypoxia elicits several unique, serotonindependent mechanisms of plasticity in the central neural control of breathing in adult rats. CIH-induced plasticity included an augmentation of the short-term hypoxic phrenic response, an abolition of post-hypoxia frequency decline and an enhanced phrenic LTF. Enhanced central neural integration of carotid chemoafferent inputs was sufficient to account for the augmented short-term hypoxic phrenic response after CIH. Because methysergide and ketanserin both reversed $\mathrm{CIH}$-induced effects on the short-term hypoxic phrenic response and post-hypoxia frequency decline, both are serotonin-dependent mechanisms. The differential effects of methysergide and ketanserin on enhanced phrenic LTF suggest that $\mathrm{CIH}$ induces additional, non-5- $\mathrm{HT}_{2}$ serotonin receptor subtypes that contribute to this unique form of "metaplasticity" in respiratory control.

\section{Short-term hypoxic phrenic response}

An augmented short-term hypoxic phrenic response was evident in $\int \mathrm{Phr}$, but only when $\mathrm{PaO}_{2}$ was $<45 \mathrm{mmHg}$ (Fig. 2). This effect is similar to results from studies of intermittent hypoxia "training" in human subjects. Serebrovskaya et al. (1999) report that three hypoxic episodes $(7-8 \%)$ of 5-6 min for 14 consecutive days in humans increased the ventilatory response to moderate (increased by $96 \%$ at $45 \mathrm{mmHg}$ ), but not mild $(70-80 \mathrm{mmHg}$ ) hypoxia. Thus, intermittent hypoxia augments both short-term hypoxic ventilatory and phrenic responses, but only during moderate to severe hypoxia.

Although the detailed mechanism or mechanisms of increased short-term hypoxic phrenic or ventilatory responses and its relationship to $\mathrm{PaO}_{2}$ are unknown, our experiments represent a first step toward such an understanding. By electrically stimulating the carotid sinus nerve and recording the phrenic nerve response, we evaluated the central integration of chemoafferent inputs, bypassing potential changes in carotid body chemosensory transduction. The magnitude of $\int \mathrm{Phr}$ responses to carotid sinus nerve stimulation rates $>5-8 \mathrm{~Hz}$ corresponded closely to the short-term hypoxic phrenic response (control, 100\%; CIH, 200-300\%). Thus, changes in central neural integration are sufficient to account for an augmentation of the short-term hypoxic phrenic response after CIH. This conclusion does not rule out an additional effect of CIH on carotid body sensitivity.

Although CIH had little effect on hypoxic frequency responses, carotid sinus nerve stimulation responses were enhanced at stimulation frequencies representative of chemoafferent activity during hypoxia (Vidruk et al., 2001). At $>8 \mathrm{~Hz}$, the difference between $\mathrm{CIH}$ and control rats decreased, suggesting the onset of intensity-dependent inhibitory reflexes. The differential effects of $\mathrm{CIH}$ on frequency responses to hypoxia versus carotid sinus nerve stimulation are difficult to explain, but may arise from inhibitory mechanisms elicited by hypoxia that mask the enhanced chemoafferent integration.

The CIH-induced augmentation of the short-term hypoxic phrenic response requires $\left(5-\mathrm{HT}_{2}\right)$ serotonin receptor activation and, therefore, appears to result from serotonin-dependent central neural plasticity. Details concerning the location of the relevant serotonin receptors cannot be determined from the present experiments.

\section{Post-hypoxia frequency decline}

It has been hypothesized that post-hypoxia frequency decline results, at least in part, from the actions of inhibitory $\alpha_{2}$ receptors on brainstem respiratory neurons (Bach and Mitchell, 1999) (but see, Coles et al., 1998). Previously, we suggested that the noradrenergic neurons relevant to post-hypoxia frequency decline are subject to inhibitory $\left(5-\mathrm{HT}_{2}\right)$ serotonergic modulation (Kinkead et al., 1999). CIH could, thus, abolish post-hypoxia frequency decline by increasing serotonergic inhibition of noradrenergic neurons, diminishing $\left(\alpha_{2}\right)$ adrenergic receptor-mediated inhibition of phrenic burst frequency. By reducing serotonergic modulation of noradrenergic neurons, methysergide or ketanserin would increase their activity, norepenephrine release, and $\alpha_{2}$ adrenoreceptor activation, thus restoring post-hypoxia frequency decline.

\section{Phrenic long-term facilitation}

The expression of neural plasticity (e.g., LTF) is itself subject to modification by experience, a concept recently referred to as "metaplasticity" (Abraham and Bear, 1996). The effect or effects of CIH on phrenic LTF and post-hypoxia frequency decline represent forms of metaplasticity in respiratory control. Kinkead et al. (1998) demonstrated that phrenic LTF is enhanced after 
sensory denervation of the cervical spinal cord via chronic cervical dorsal rhizotomy. Because ketanserin blocked the enhanced LTF and because serotonin terminal density was increased near labeled phrenic motoneurons, we suggested that dorsal rhizotomy increased the capacity for serotonergic modulation of phrenic motoneurons, thereby enhancing LTF (Kinkead et al., 1998). Although our working hypothesis is that both cervical dorsal rhizotomy and CIH enhance phrenic LTF by augmenting the capacity for serotonergic modulation of phrenic motoneurons, there are clear differences in their respective mechanism or mechanisms. For example, unlike $\mathrm{CIH}$, dorsal rhizotomy does not affect the apneic threshold, the short-term hypoxic phrenic response, or post-hypoxia frequency decline (Kinkead et al., 1998).

Changes in serotonergic modulation may enhance LTF after CIH by: (1) changes in serotonin terminal density and serotonin release, (2) altered serotonin transport protein function, (3) colocalized and co-released neuropeptides, (4) changes in presynaptic or postsynaptic serotonin receptor subtypes, or (5) changes in presynaptic or postsynaptic signaling pathways. Given the complex nature of serotonergic modulation, it is difficult to make conclusions concerning the detailed synaptic or cellular changes that give rise to $\mathrm{CIH}$-induced plasticity. However, the differential effects of methysergide and ketanserin on enhanced phrenic LTF after CIH may provide one clue. The failure of the more selective antagonist ketanserin to block LTF after CIH may suggest the induction of additional, non-5- $\mathrm{HT}_{2}$ serotonin receptor subtypes.

\section{Sustained versus intermittent hypoxia}

The concept that intermittent (spaced) versus sustained (massed) stimulation is more effective at eliciting certain forms of neuroplasticity has been established in several experimental models. For example, intermittent stimulation is more effective than sustained stimulation in eliciting serotonin-dependent synaptic plasticity in Aplysia (Mauelshagen et al., 1998), conditioned foot contractions in Hermissenda (Muzzio et al., 1999), olfactory conditioning in Drosophila and honeybees (Sandoz et al., 1995; Beck et al., 2000), habituation to danger stimuli in crabs (Freudenthal and Romano, 2000), and contextual fear conditioning, spatial learning, and socially transmitted food preferences in mice (Kogan et al., 1997). Other learning paradigms exhibit similar pattern sensitivity (for references, see Muzzio et al., 1999; Mitchell et al., 2001).

Intermittent and sustained hypoxia appear to evoke fundamentally different respiratory-related responses and/or mechanisms. For example, LTF is elicited by episodic, but not sustained hypoxia in anesthetized rats (Baker and Mitchell, 2000a) and unanesthetized goats (Turner and Mitchell, 1997 vs Dwinell et al., 1997). LTF is elicited by a relatively small number of hypoxic episodes (3-10) over a period of minutes to hours. Until this study, there was insufficient information to contrast the respective effects of chronic (days to weeks) intermittent and sustained hypoxia on respiratory control.

Chronic intermittent and sustained hypoxia both cause hyperventilation in unanesthetized animals (Bisgard and Neubauer, 1995) (E. B. Olson, D. D. Fuller, and G. S. Mitchell, unpublished observations), decrease the $\mathrm{CO}_{2}$-apneic threshold in anesthetized rats (Dwinell and Powell, 1999; this study), and augment the short-term hypoxic ventilatory response (Bisgard and Forster, 1996; Powell et al., 1998; Serebrovskaya et al., 1999; this study). However, increased carotid body sensitivity plays a pivotal role in ventilatory acclimatization to chronic sustained hypoxia (Nielsen et al., 1988; Bisgard and Forster, 1996), with lesser effects on central integration of chemoafferent inputs (Dwinell and Powell, 1999). Although there may also be effects of CIH on carotid body sensitivity (Prabhakar, 2001), CIH appears to have greater impact on central neural plasticity.

Using the carotid sinus nerve stimulation protocol developed in our laboratory (Ling et al., 1997), Dwinell and Powell (1999) demonstrated that sustained hypoxia ( $7 \mathrm{~d}$ ) augments the central integration of chemoafferent inputs, although these effects differed somewhat from our results after CIH. Specifically, chronic sustained hypoxia augments frequency responses to carotid sinus nerve stimulation, with marginal effects on amplitude (significant as percentage of baseline, not as percentage of maximum). In contrast, $\int \mathrm{Phr}$ responses to carotid sinus nerve stimulation are clearly augmented after $\mathrm{CIH}$, with marginal frequency response increases.

An additional distinction between $\mathrm{CIH}$ and sustained hypoxia is that ventilatory acclimatization to sustained hypoxia is insensitive to serotonin depletion (Olson, 1987) or methysergide pretreatment (Herman et al., 1999), whereas serotonin receptor antagonists attenuate $\mathrm{CIH}$-induced plasticity (this study). Thus, our results suggest that chronic intermittent hypoxia increases the capacity for central serotonergic modulation, whereas chronic sustained hypoxia acts primarily by nonserotonergic, peripheral chemoreceptor mechanisms.

\section{Physiological significance}

Our results indicate that intermittent stimulation of the hypoxic ventilatory control system enhances future system performance (plasticity and metaplasticity) by serotonin-dependent central neural mechanisms. The potential of intermittent hypoxia to elicit plasticity is generating considerable interest in the respiratory control community because of the potential significance of intermittent hypoxia to patients with sleep-disordered breathing. However, conclusions concerning the applicability of our results to sleep-disordered breathing must remain tentative. Our $\mathrm{CIH}$ model was not designed to simulate sleep apneic episodes because it consists of nocturnal (i.e., awake in rats), hypocapnic hypoxic episodes of a relatively long duration $(5 \mathrm{~min})$. Although there are intriguing similarities, the impact of each of these variables must be considered before interpreting our results in the context of sleep-disordered breathing. Regardless, these studies provide a robust and novel experimental model to study serotonin-dependent plasticity in the respiratory motor control system of adult mammals. Such a model may be a very useful addition to the study of serotonin-dependent neuroplasticity in general.

\section{REFERENCES}

Abraham WC, Bear MF (1996) Metaplasticity: the plasticity of synaptic plasticity. Trends Neurosci 19:126-130.

Baker TL, Mitchell GS (2000a) Episodic, but not continuous hypoxia elicits long-term facilitation of phrenic motor output. J Physiol (Lond) 529:215-219.

Baker TL, Mitchell GS (2000b) Spinal protein synthesis inhibition attenuates serotonin-dependent long term facilitation of phrenic motor output. Soc Neurosci Abstr 26:1458.

Baker TL, Mitchell GS (2001) Spinal serotonin receptor activation is necessary for phrenic long- term facilitation following episodic hypoxia. Fed Proc 15:A422.

Bach KB, Mitchell GS (1996) Hypoxia-induced long-term facilitation of respiratory activity is serotonin dependent. Respir Physiol 104:251-260.

Bach KB, Kinkead R, Mitchell GS (1999) Post-hypoxia frequency decline in rats: sensitivity to repeated hypoxia and alpha ${ }_{2}$-adrenoreceptor antagonism. Brain Res 817:25-33.

Beck CDO, Schroeder B, Davis L (2000) Learning performance of nor- 
mal and mutant Drosophila after repeated conditioning trials with discrete stimuli. J Neurosci 20:2944-2953.

Bisgard GE, Forster HV (1996) Ventilatory responses to acute and chronic hypoxia. In: Handbook of physiology: environmental physiology (Fregly MJ, Blatteis CM, ed), pp 1207-1239. Washington, DC: American Physiological Society.

Bisgard GE, Neubauer JA (1995) Peripheral and central effects of hypoxia. In: Lung biology in health and disease: regulation of breathing (Dempsey JA, Pack AI, ed), pp 617-668. New York: Dekker.

Coles SK, Dick TE (1996) Neurones in the ventrolateral pons are required for post-hypoxic frequency decline in rats. J Physiol (Lond) 497:79-94.

Coles SK, Ernsberger P, Dick TE (1998) Post-hypoxic frequency decline does not depend on alpha ${ }_{2}$-adrenergic receptors in the adult rat. Brain Res 794:267-273.

Dwinell MR, Powell FL (1999) Chronic hypoxia enhances the phrenic nerve response to arterial chemoreceptor stimulation in anesthetized rats. J Appl Physiol 87:817-823.

Dwinell MR, Janssen PL, Bisgard GE (1997) Lack of long term facilitation of ventilation after exposure to hypoxia in goats. Respir Physiol 108:1-9.

Eldridge FL, Millhorn DE (1986) Oscillation, gating, and memory in the respiratory control system. In: Handbook of physiology: the respiratory system (Fishman AP, ed), pp 93-114. Washington, DC: American Physiological Society.

Freudenthal R, Romano A (2000) Participation of Rel/NF-kappaB transcription factors in long-term memory in the crab Chasmagnathus. Brain Res 855:274-281.

Fuller DD, Bach KB, Baker TL, Kinkead R, Mitchell GS (2000) Long term facilitation of phrenic motor output. Respir Physiol 121:135-146.

Fuller DD, Zabka AG, Baker TL, Mitchell GS (2001) Phrenic long-term facilitation requires 5-HT receptor activation during but not following episodic hypoxia. J Appl Physiol 90:2001-2006.

Hayashi F, Coles SK, Bach KB, Mitchell GS, McCrimmon DR (1993) Time-dependent phrenic nerve responses to carotid afferent activation: intact vs. decerebellate rats. Am J Physiol 265:R811-R819.

Herman JK, O'Halloran KD, Mitchell GS, Bisgard GE (1999) Methysergide augments the acute, but not the sustained, hypoxic ventilatory response in goats. Respir Physiol 118:25-37.

Kandel ER, Schwartz JH, Jessell TM (2000) Principles of neural science. New York: McGraw-Hill.

Kinkead R, Mitchell GS (1999) Time-dependent hypoxic ventilatory response in rats: effects of ketanserin and 5-carboxamidotryptamine. Am J Physiol 277:R658-R666.

Kinkead R, Zhan WZ, Prakash YS, Bach KB, Sieck GC, Mitchell GS (1998) Cervical dorsal rhizotomy enhances serotonergic innervation of phrenic motoneurons and serotonin-dependent long-term facilitation of respiratory motor output in rats. J Neurosci 18:8436-8443.

Kogan JH, Frankland PW, Blendy JA, Coblentz J, Marowitz Z, Schutz G, Silva AJ (1997) Spaced training induces normal long term memory in CREB mutant mice. Curr Biol 1:1-11.

Ling L, Olson EB, Vidruk EH, Mitchell GS (1997) Integrated phrenic responses to carotid afferent stimulation in adult rats following perinatal hyperoxia. J Physiol (Lond) 500:787-796.

Ling L, Olson EB, Mitchell GS (1998) Chronic intermittent hypoxia enhances the hypoxic ventilatory control system. FASEB J 12:A781.

Ling L, Bach KB, Kinkead R, Olson EB, Mitchell GS (1999) Enhancement of the hypoxic ventilatory responses following chronic intermittent hypoxia is serotonin-dependent. FASEB J 13:A166.

Ling L Olson EB, Johnson SM, Mitchell GS (2000) Phrenic responses to electrical stimulation of carotid sinus nerve in rats following chronic intermittent hypoxia. FASEB J 14:A77.

Mauelshagen J, Sherff CM, Carew TJ (1998) Differential induction of long-term synaptic facilitation by spaced and massed applications of serotonin at sensory neuron synapses of Aplysia californica. Learn Mem 5:246-256

McCrimmon DR, Dekin MS, Mitchell GS (1995) Glutamate, GABA, and serotonin in ventilatory control. In: Lung biology in health and disease: regulation of breathing (Dempsey JA, Pack AI, ed), pp 151218. New York: Dekker.

Millhorn DE, Eldridge FL, Waldrop TG (1980a) Prolonged stimulation of respiration by a new central neural mechanism. Respir Physiol 41:87-103.

Millhorn DE, Eldridge FL, Waldrop TG (1980b) Prolonged stimulation of respiration by endogenous central serotonin. Respir Physiol 42:171-198.

Mitchell GS, Douse MA, Foley KT (1990) Receptor interactions in modulating ventilatory activity. Am J Physiol 259:R911-R920.

Mitchell GS, Bach KB, Martin PA, Foley KT (1993) Modulation and plasticity of the exercise ventilatory response. Funct Biol Syst 23:269-277.

Mitchell GS, Baker TL, Nanda SA, Fuller DD, Zabka AG, Hodgeman BA, Bavis RW, Mack KJ, Olson EB (2001) Intermittent hypoxia and respiratory plasticity. J Appl Physiol 90:2466-2475.

Muzzio IA, Ramirez RR, Talk AC, Matzel LD (1999) Interactive contributions of intracellular calcium and protein phosphatases to massedtrials learning deficits in Hermissenda. Behav Neurosci 113:103-117.

Nielsen AM, Bisgard GE, Vidruk EH (1988) Carotid chemoreceptor activity during acute and sustained hypoxia in goats. J Appl Physiol 65:1796-1802.

Olson EB (1987) Ventilatory adaptation to hypoxia occurs in serotonindepleted rats. Respir Physiol 69:227-235.

Poon C (1996a) Self-tuning optimal regulation of respiratory motor output by Hebbian covariance learning. Neural Networks 9:1367-1383.

Poon C (1996b) Synaptic plasticity and respiratory control. In: Bioengineering approaches to pulmonary physiology and medicine (Khoo M, ed), pp 93-113. New York: Plenum.

Powell FL, Milsom WK, Mitchell GS (1998) Time domains of the hypoxic ventilatory response. Respir Physiol 112:123-134.

Prabhakar NR (2001) Oxygen sensing during intermittent hypoxia: cellular and molecular mechanisms. J Appl Physiol 90:1986-1994.

Sandoz JC, Roger B, Pham-Delegue MH (1995) Olfactory learning and memory in the honeybee: comparison of different classical conditioning procedures of the proboscis extension response. C R Acad Sci III 18:749-755.

Serebrovskaya TV, Karaban IN, Kolesnikova EE, Mishunia TM, Kuzminskaya LA, Serbrovsky AN, Swanson RJ (1999) Human hypoxic ventilatory response with blood dopamine content under intermittent hypoxic training. Can J Physiol Pharmacol 77:967-973.

Turner DL, Mitchell GS (1997) Long-term facilitation of ventilation following repeated hypoxic episodes in awake goats. J Physiol (Lond) 2:543-550.

Vidruk EH, Olson Jr EB, Ling L, Mitchell GS (2001) Carotid body chemoreceptor responsiveness in adult rats. J Physiol (Lond) 53:165-170.

Yanow SK, Manseau F, Hislop J, Casellucci VF, Sossin WS (1998) Biochemical pathways by which serotonin regulates translation in the nervous system of Aplysia. J Neurochem 70:572-583.

Zigmond MJ, Bloom FE, Landis SC, Roberts JL, Squire LR (1999) Fundamentals of neuroscience. New York: Academic. 